\title{
Pulmonary exacerbations as indicators of progression of lung disease in young children with CF
}

\author{
Don B Sanders, ${ }^{1}$ Christopher Hooper Goss ${ }^{2,3}$
}

The approval of ivacaftor by the European Medicines Agency (EMA) and the US Food and Drug Administration (US FDA) and the ongoing development of other drugs that target the underlying defect that causes cystic fibrosis (CF) have generated a great deal of excitement and hope for patients with CF. ${ }^{12}$ To truly maximise the potential benefits of these drugs, they will need to be administered before irreversible lung disease (eg, bronchiectasis) develops. Most patients with CF who have taken part in therapeutic drug trials have been at least 6 years of age, when most patients begin to be able to perform spirometry, the most commonly used endpoint in CF therapeutic trials. However, an observational study in Australian Respiratory Early Surveillance Team for Cystic Fibrosis (AREST CF) demonstrated that structural lung disease, including bronchiectasis, may

\footnotetext{
${ }^{1}$ Department of Pediatrics, University of Wisconsin, Madison, Wisconsin, USA; ${ }^{2}$ Division of Pulmonary and Critical Care Medicine, Department of Medicine, University of Washington, Seattle, Washington, USA; ${ }^{3}$ Division of Pulmonary Medicine, Department of Pediatrics, Seattle Children's Hospital, Seattle, Washington, USA
}

Correspondence to Dr Christopher Hooper Goss, Division of Pulmonary and Critical Care Medicine, Department of Medicine, University of Washington Medical Center, Campus Box 356522, 1959 NE Pacific, Seattle, WA 98195, USA; goss@u.washington.edu be present even in infancy. ${ }^{3}$ Thus, to minimise the progression of lung disease, we must initiate treatment as early as safely possible for those patients who are at risk for developing lung disease. The challenge in obtaining EMA or FDA approval for new therapeutic interventions to be administered in early life, where the progression of lung disease occurs in a 'black box', is demonstrating safety and efficacy in children too young to perform traditional spirometry. Given that pulmonary exacerbations occur frequently even in young children, they offer an inviting clinical endpoint for future studies in this age group. The FDA defines clinical endpoints as direct measures of how a patient feels, functions or survives. ${ }^{4}$ Pulmonary exacerbations are clinically meaningful endpoints that are associated with survival, ${ }^{5}$ future deterioration of spirometry ${ }^{6}$ and increased bronchiectasis, ${ }^{7}$ consume significant clinical resources ${ }^{8}$ and impact quality of life ${ }^{9}$ in studies of older children and adults.

Byrnes et $a l^{10}$ add strength to the argument that pulmonary exacerbations can be a meaningful clinical endpoint for young children. They demonstrated that there are associations between frequent pulmonary exacerbations, especially in the first 2 years of life, and decreased spirometry $\left(\mathrm{FEV}_{1}\right)$ at age 5, and between more frequent pulmonary exacerbations treated with intravenous antibiotics and the presence of bronchiectasis on chest CT and decreased weight for age at age 5 . The study enrolled children with CF before 6 months of age after being identified via newborn screening. The original studies of the risks and benefits of new born screening (NBS) for CF failed to demonstrate an improvement in pulmonary outcomes as children reached adolescence. ${ }^{11}$ This study clearly highlights an opportunity provided by NBS (ie, to identify and appropriately treat pulmonary exacerbations in the first few years of life) to improve long-term pulmonary outcomes.

One of the challenges with pulmonary exacerbations in this age group is that they might merely represent stochastic events related to viral infections that might not be preventable. The authors point out that the frequency of pulmonary exacerbations is somewhat similar to the frequency of viral upper respiratory tract infections that occur in healthy children without $\mathrm{CF}^{12}$ We know that children with $\mathrm{CF}$ are more likely to have prolonged viral infections and of greater severity. ${ }^{13}$ The presence of rhinovirus $^{14}$ and respiratory syncytial virus ${ }^{15}$ may enable Pseudomonas to more easily infect airway epithelial cells from patients with CF. Of concern, the recent Infant Study of Inhaled Saline (ISIS) in CF study found that inhaled hypertonic saline failed to decrease the rate of pulmonary exacerbations in children aged 4-60 months with CF using an alternative definition. ${ }^{16}$ Was the definition wrong, or do we need a number of endpoints to assess treatment benefit in small children? Studies of disease-modifying drugs will clearly not only need to evaluate pulmonary exacerbations as an endpoint in this age group but also look to other outcome measures to ensure success. In the ISIS study, a subgroup of patients performed infant pulmonary function testing, and 
patients who received inhaled hypertonic saline had a significantly larger mean improvement in forced expiratory volume in $0.5 \mathrm{~s}^{16}$ Serial chest CT scans have demonstrated structural lung disease, such as bronchiectasis, that is persistent and progressive even in young children with $\mathrm{CF}^{17}$ The primary endpoint of an ongoing study of azithromycin for young children with $\mathrm{CF}$ is the prevention of bronchiectasis on chest $\mathrm{CT}$ at age $3 .^{18}$ Additionally, the lung clearance index (LCI), an outcome measure using the multiple-breath washout (MBW) method, has been shown to be repeatable, reproducible and sensitive in detecting the presence of lung disease in children with $\mathrm{CF}$ as young as 4 months of age. ${ }^{19}$ LCI in 35 -year-olds with CF is predictive of future LCI at $6-10$ years of age. ${ }^{20}$ It should be noted that neither infant pulmonary function testing nor LCI have been validated as endpoints by either the EMA or the FDA.

Many questions remain regarding pulmonary exacerbations in young children with CF. Do frequent (viral) pulmonary exacerbations lead to global obstructive lung disease and result in lower $\mathrm{FEV}_{1}$ at age 5, whereas more significant (presumably bacterial) pulmonary exacerbations that lead a clinician to treat with intravenous antibiotics lead to focal injury (bronchiectasis)? In that case, should antibiotic prophylaxis be used, since lower pulmonary exacerbation rates were found in areas that used prophylaxis, and does that make up for the potential risks of earlier Pseudomonas aeruginosa acquisition seen in children with CF who receive antibiotic prophylaxis? ${ }^{21}$ Or is it that patients who already have bronchiectasis are more likely to require intravenous antibiotics for treatment? Baseline chest imaging was not available in this cohort, although the AREST-CF study would indicate that at least some of these patients had bronchiectasis early on. ${ }^{3}$ It is not known if the rate of pulmonary exacerbations can be reduced in this age group through other therapeutic interventions. The ISIS study showed that hypertonic saline could not reduce the rate of pulmonary exacerbations in infants with $\mathrm{CF}{ }^{16}$ Similar studies of other therapies approved for older children and adults with CF (eg, azithromycin, dornase $\alpha$, inhaled tobramycin) have not been conducted. Finally, without spirometry, it is difficult to assess whether young children ultimately recover following pulmonary exacerbations. ${ }^{22}$

There have long been calls for a standard definition of a pulmonary exacerbation. Such a definition cannot work for all age groups. Clearly for small children, using a wide net to define an exacerbation was meaningful; patients experiencing these events went on to have lower $\mathrm{FEV}_{1}$, weight for age and/or more bronchiectasis. To satisfy regulatory agencies' definition of clinically meaningful endpoints, additional patient (parent)-reported outcomes may need to be included in any definition of pulmonary exacerbation. ${ }^{23}$ A standard pulmonary exacerbation definition for this age group is necessary, at least in order to easily compare results between different studies. In the meantime, it would seem that, at least for young children with $\mathrm{CF}$, more aggressive therapy may be indicated, even for symptoms that may be due 'only' to a viral infection. While there are many important questions that need to be addressed, the current report has begun to open the 'black box' to enable us to monitor the progression of CF lung disease in young children.

Contributors Both authors were involved in drafting and reviewing the manuscript for important intellectual content.

Competing interests $\mathrm{CHG}$ receives funding from the US Cystic Fibrosis Foundation, the NIH (R01HL103965, R01 Al101307, P30 DK089507) and the FDA

(R01 FD003704). CHG has participated on advisory board and received an unrestricted grant from Transave Inc; participated on an advisory board for KaloBios Pharm; and received an unrestricted grant from Vertex Pharmaceuticals to perform secondary data analyses. DBS has received funding from the US Cystic Fibrosis Foundation and the $\mathrm{NHH}$.

Provenance and peer review Commissioned; internally peer reviewed.

To cite Sanders DB, Goss CH. Thorax 2013;68:608-609.

Published Online First 29 March 2013

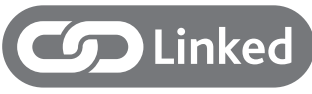

- http://dx.doi.org/10.1136/thoraxjnl-2012-202342

Thorax 2013;68:608-609.

doi:10.1136/thoraxjnl-2013-203262

\section{REFERENCES}

1 Ramsey BW, Davies J, McElvaney NG, et al. A CFTR potentiator in patients with cystic fibrosis and the G551D mutation. N Engl J Med 2011;365:1663-72.

2 Accurso FJ, Rowe SM, Clancy JP, et al. Effect of VX-770 in persons with cystic fibrosis and the G551D-CFTR mutation. N Eng/ I Med 2010;363:1991-2003.

3 Stick SM, Brennan S, Murray C, et al. Bronchiectasis in infants and preschool children diagnosed with cystic fibrosis after newborn screening. J Pediatr 2009;155:623-8.e1.

4 Biomarkers Definitions Working Group. Biomarkers and surrogate endpoints: preferred definitions and conceptual framework. Clin Pharmacol Ther 2001;69:89-95.
5 Liou TG, Adler FR, Fitzsimmons SC, et al. Predictive 5-year survivorship model of cystic fibrosis. Am J Epidemiol 2001;153:345-52.

6 Sanders DB, Bittner RC, Rosenfeld M, et al. Pulmonary exacerbations are associated with subsequent $\mathrm{FEV}(1)$ decline in both adults and children with cystic fibrosis. Pediatr Pulmonol 2011;46:393-400.

7 Brody AS, Sucharew H, Campbell JD, et al. Computed tomography correlates with pulmonary exacerbations in children with cystic fibrosis. Am J Respir Crit Care Med 2005;172:1128-32.

8 Briesacher BA, Quittner AL, Fouayzi H, et al. Nationwide trends in the medical care costs of privately insured patients with cystic fibrosis (CF), 2001-2007. Pediatr Pulmonol 2011;46:770-6.

9 Britto MT, Kotagal UR, Hornung RW, et al. Impact of recent pulmonary exacerbations on quality of life in patients with cystic fibrosis. Chest 2002;121:64-72.

10 Byrnes CA, Vidmar S, Cheney JL, et al. Prospective evaluation of respiratory exacerbations in children with cystic fibrosis from newborn screening to 5 years of age. Thorax 2013;68:643-51.

11 Farrell PM, Li Z, Kosorok MR, et al. Bronchopulmonary disease in children with cystic fibrosis after early or delayed diagnosis. Am J Respir Crit Care Med 2003;168:1100-8.

12 Kusel MM, de Klerk N, Holt PG, et al. Occurrence and management of acute respiratory illnesses in early childhood. J Paediatr Child Health 2007:43:139-46.

13 van Ewijk BE, van der Zalm MM, Wolfs TF, et al. Prevalence and impact of respiratory viral infections in young children with cystic fibrosis: prospective cohort study. Pediatrics 2008;122:1171-6.

14 Chattoraj SS, Ganesan S, Jones AM, et al. Rhinovirus infection liberates planktonic bacteria from biofilm and increases chemokine responses in cystic fibrosis airway epithelial cells. Thorax 2011;66:333-9.

15 Van Ewijk BE, Wolfs TF, Aerts PC, et al. RSV mediates Pseudomonas aeruginosa binding to cystic fibrosis and normal epithelial cells. Pediatr Res 2007:61:398-403.

16 Rosenfeld M, Ratjen F, Brumback L, et al. Inhaled hypertonic saline in infants and children younger than 6 years with cystic fibrosis: the ISIS randomized controlled trial. JAMA 2012;307:2269-77.

17 Mott LS, Park J, Murray CP, et al. Progression of early structural lung disease in young children with cystic fibrosis assessed using $\mathrm{CT}$. Thorax 2012;67:509-16.

18 Sly PD, Stick SM. Prevention of bronchiectasis in infants with cystic fibrosis (COMBATCF). In: ClinicalTrials.gov [Internet]. Bethesda, MD: National Library of Medicine (US), 2000. [cited 2013 Feb 3]. http://clinicaltrials.gov/show/NCT01270074 NLM Identifier: NCT01270074 (accessed 29 Jan 2013).

19 Belessis Y, Dixon B, Hawkins G, et al. Early cystic fibrosis lung disease detected by bronchoalveolar lavage and lung clearance index. Am J Respir Crit Care Med 2012;185:862-73.

20 Aurora P, Stanojevic S, Wade A, et al. Lung clearance index at 4 years predicts subsequent lung function in children with cystic fibrosis. Am J Respir Crit Care Med 2011;183:752-8.

21 Smyth AR, Walters S. Prophylactic anti-staphylococcal antibiotics for cystic fibrosis. Cochrane Database Syst Rev 2012;12:CD001912.

22 Sanders DB, Bittner RC, Rosenfeld M, et al. Failure to recover to baseline pulmonary function after cystic fibrosis pulmonary exacerbation. Am J Respir Crit Care Med 2010;182:627-32.

23 Mayer-Hamblett N, Ramsey BW, Kronmal RA. Advancing outcome measures for the new era of drug development in cystic fibrosis. Proc Am Thorac Soc 2007;4:370-7. 